\title{
TAMBAL BAN SEPEDA MOTOR YANG ERGONOMIS MENGGUNAKAN ARDUINO UNO
}

\author{
Jusnita $^{1 *}$, Danil ${ }^{2}$ \\ Jurusan Mesin Otomotif Fakultas Teknik Universitas Muhammadiyah Riau \\ Jl. Tuaku Tambusai Pekanbaru - Riau \\ Email: jusnita@umri.ac.id
}

\begin{abstract}
Tire patch is an activity to repair the tire incompletely only on the part that is leaking. the tire patch tool uses canned gas as a heater, the use of canned gas as a tire heater turns out to have many shortcomings such as the results of the patch being less sticky, the patching time is quite long and it costs a lot of money to buy canned gas. The methodology used in this study is the method of validity, namely testing the hot temperature on an Arduino Uno-based automatic tire patch with a Bluetooth connection. The result of designing an ergonomic motorcycle tire patch tool based on Arduino Uno. The control system tool can work in accordance with its supporting instruments by detecting hot temperatures to operating the device using a Bluetooth connection, there are two types of support systems which are often referred to as software and hardware, so the design process is carried out on both of these supports. The test was carried out 3 times. The first test using a temperature of 80-100 oC takes 3 minutes 28 seconds. The second test using a temperature of 100-120 oC takes 4 minutes 30 seconds with poor results because the results of the patch cannot withstand a large load and cannot withstand being used for too long, while the last or third test uses a temperature of 120-160 oC with the required time. 5 minutes 40 seconds with good patching results.
\end{abstract}

Keywords: Tire Patch, Arduino Uno, Software and Hardware

\begin{abstract}
Tambal ban adalah kegiatan memperbaiki ban secara tidak menyeluruh hanya pada bagian yang bocor. alat tambal ban menggunakan gas kaleng sebagai pemanas, penggunaan gas kaleng sebagai pemanas tambal ban ternyata memiliki banyak kekurangan seperti hasil tambalan yang kurang lengket, waktu untuk menambal cukup lama dan mengeluarkan biaya yang mahal untuk membeli gas kaleng. Metodologi yang digunakan dalam penelitian ini metode validitas yaitu pengujian temperatur panas terhadap alat tambal ban otomatis berbasis arduino uno dengan koneksi bloetooth. Hasil perancangan alat tambal ban sepeda motor yang ergonomis berbasis arduino uno. Alat sistem kontrol tersebut dapat bekerja sesuai dengan instrumen pendukung-pendukungnya dengan pendeteksian suhu panas sampai dengan pengoperasian alat dengan menggunakan koneksi bloetooth, sistem pendukung ada dua jenis sistem yang sering disebut sebagai software dan hardware, sehingga proses perancangan ini dilaksanakan pada kedua pendukung tersebut. Pengujian dilakukan sebanyak 3 kali. Pengujian pertama dengan menggunakan suhu $80-100{ }^{\circ} \mathrm{C}$ membutuhkan waktu 3 menit 28 detik. Pengujian kedua menggunakan suhu $100-120{ }^{\circ} \mathrm{C}$ membutuhkan waktu 4 menit 30 detik dengan hasil kurang baik karena hasil tambalan tidak bisa menahan beban yang besar dan tidak tahan digunakan terlalu lama, sedangkan pada pengujian terakhir atau ketiga menggunakan suhu $120-160{ }^{\circ} \mathrm{C}$ dengan waktu yang dibutuhkan 5 menit 40 detik dengan hasil tambalan yang baik.
\end{abstract}

Kata kunci: Tambal Ban, Arduino Uno, Software dan Hardware 


\section{Pendahuluan}

Tambal ban adalah kegiatan memperbaiki ban secara tidak menyeluruh hanya pada bagian yang bocor. Ban terdiri dari tiga macam yaitu : a. ban dalam adalah ban yang berada di dalam lebih tipis, tempat udara dipompakan, b. ban luar adalah ban yang berada di luar, tebal, keras sebagai lapis penutup pelindung ban dalam, c. ban tanpa Tubeless adalah ban yang dirancang tanpa menggunakan ban dalam, (Anugrah Erlangga, 2012)

Perkembangan zaman yang semakin pesat saat ini memunculkan berbagai jenis alat tambal ban salah satunya menggunakan gas kaleng sebagai pemanas, penggunaan gas kaleng sebagai pemanas tambal ban ternyata memiliki banyak kekurangan seperti hasil tambalan yang kurang lengket, waktu untuk menambal cukup lama dan mengeluarkan biaya yang mahal untuk membeli gas kaleng. Perancangan peralatan secara ergonomis perlu dilakukan yang berpedoman pada prinsip- prinsip ergonomi, (Wignjosoebroto, 2008)

Ergonomi dapat didefinisikan sebagai studi tentang aspek-aspek manusia dalam lingkungan kerjanya ditinjau secara anatomi, fisiologi, psikologi, engineering, manajemen, dan desain/perancangan. Ergonomi berkenaan dengan optimasi, efisiensi, kesehatan, keselamatan, dan kenyamanan manusia di tempat kerja, rumah, dan dimana saja manusia berada (Nurmianto, 2004). Sebelum melakukan perancangan alat juga tentu saja kita harus memperhatikan aspek ergonomi dari alat tersebut. Alat tambal ban ini dirancang sedemikian rupa agar mudah digunakan oleh kalangan masyarakat, seperti bagian handle stick dan base yang dibuat supaya memudahkan memegang pada saat akan melakukan penekanan dan juga elemen pemanas langsung menyatu pada bagian base.

Rancang bangun tambal ban sepeda motor yang ergonomis memiliki keamanan dan desain yang baik sehingga semua orang bisa menggunakan tanpa perlu kuatir ban akan kebakar karena alat ini sudah dirancang dengan sedemikian rupa agar mudah dibawa kemana saja karena hanya memerlukan ruang yang sedikit, dari segi desain tambal ban yang ergonomis lebih diperuntukkan bagi kalangan masyarakat umum dan untuk kalangan usaha tambal ban mungkin alat ini kurang ergonomis jika digunakan terus menerus karena desain yang kecil sehingga pengguna akan menimbulkan nyeri pinggang jika tetap ingin menggunakan alat ini dapat dimodifikasi pada ukuran tanpa mempengaruhi fungsinya.

Tambal ban sepeda motor yang ergonomis berbasis arduino dengan koneksi bluetooth dengan menyambungkan ke android sebagai pengatur on/off. Mungkin sudah banyak tambal ban elektrik di pasaran, akan tetapi tambal ban elektrik yang ada dipasaran kurang efisien karena tambal ban ini harus ditunggu dan sesekali harus dilihat apakah tambalan sudah matang atau belum atau apabila terlalu lama ban malah akan meleleh. Oleh karena itu dibuat tambal ban ini untuk memudahkan dalam menambal ban hanya mengoperasikan dengan cara mengoneksikan bloetooth ke aplikasi hp android atau dengan bantuan tombol pada kotak arduino.

\section{Metodologi}

Metodologi yang digunakan dalam penelitian ini metode validitas yaitu pengujian temperatur panas terhadap alat tambal ban otomatis berbasis arduino uno dengan koneksi bloetooth. Tujuan dari pengujian ini adalah untuk mengetahui tingkat pemanasan dan kematangan lem ban setelah dilakukan pengujian.

\section{Hasil dan Pembahasan}

Hasil perancangan alat tambal ban sepeda motor yang ergonomis berbasis arduino uno dengan tujuan 
memaksimalkan hasil tambalan karetBhagind yang matang. Alat sistem kontrol tersebut dapat bekerja sesuai dengan instrumen pendukung-pendukungnya dengan pendeteksian suhu panas sampai dengan pengoperasian alat dengan menggunakan koneksi bloetooth, sedangkan sistem pendukung ini digolongkan menjadi dua jenis sistem yang sering disebut sebagai software dan hardware, sehingga untuk proses perancangan ini maka dilaksanakan pada kedua pendukung tersebut.

Alat tambal ban yang terdiri dari beberapa bagian yaitu, Base, Handle dan Pressing/alat penekan. Bagian-bagian tersebut didesain menggunakan Software Inventor. Desain gambar alat tambal sepeda motor ergonomis menggunakan arduino uno dapat dilihat pada gambar dibawah ini;

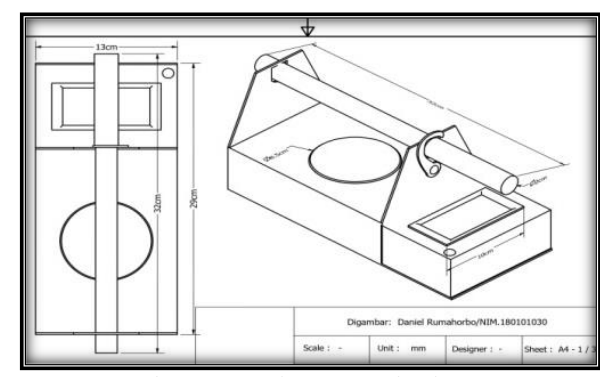

Gambar 1. Alat Tambal Ban 2D

Bagian dari alat tambal ban seperti; Base berfungsi sebagai tempat di letakkannya ban dalam pada saat dipress.

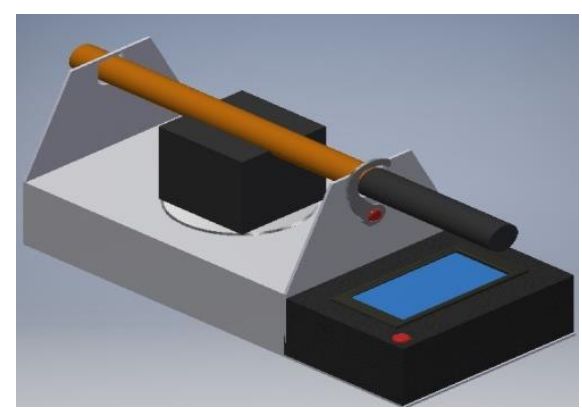

Gambar 2 Alat Tambal Ban 3D disambungkan dengan besi hollow sebagai penyangga handle dengan alat penekan. Sedangkan handle berfungsi untuk pegangan pada saat mengepress, Pressing berfungsi sebagai penekan ban ke base pada saat melakukan pemanasan. Alat pressing tersebut ditekan dengan alat handle. Perancangan Hardware

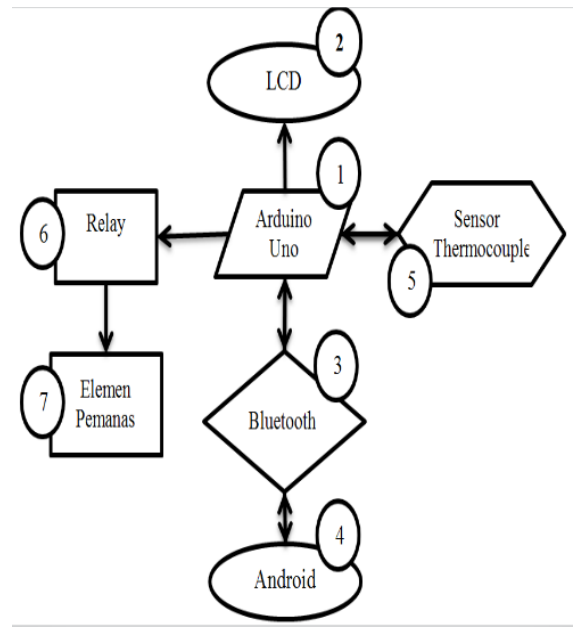

Gambar Error! No text of specified style in document.. Rangkaian Alat Tambal Ban

Untuk perancangan hardware berpedoman kepada karakteristik, fungsi dan tata letak komponen ataupun modulmodul pendukung supaya sistem kontrol dapat bekerja secara bersinambungan sehingga hasil rancangan yang disusun secara diagram blok adalah seperti yang ditunjukkan seperti pada gambar di bawah ini.

\footnotetext{
SURYA TEKNIKA Vol. 8 No. 1, Juni 2021: 274-281
} 


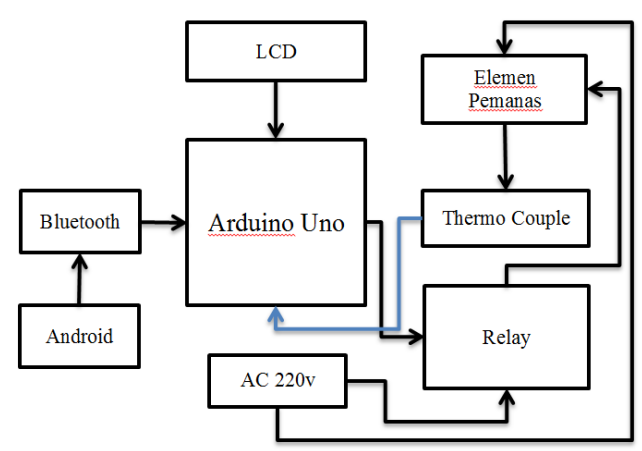

Gambar 4. Diagram Blok Sistem Kontrol

Fungsi dari masing-masing blok gambar 4 adalah sebagai berikut ini;

Sensor thermokopel, berguna untuk mengukur suhu dan kelembaban yang dimiliki output tegangan analog yang dapat diolah lebih lanjut menggunakan mikrokontroler. Sensor ini berfungsi untuk mendeteksi panas suhu elemen pemanas sehingga panas suhu elemen pemanas tersebut terdeteksi. Sensor Thermokopel ini dihubungkan dengan arduino uno pada bagian inputnya dan daya listrik sensor diambil juga dari daya listrik arduino sedangkan penempatan sensor ini dekat pada posisi element pemanas.

liquid cristal display adalah salah satu jenis display elektronik yang dibuat dengan teknologi CMOS logic yang bekerja dengan tidak menghasilkan cahaya tetapi memantulkan cahaya yang ada sekelilingnya terhadap front-lit atau mentransmisikan cahaya dari back-lit. Lcd (liquid cristal display) ini berfungsi untuk menampilkan panas suhu dan timer.

Arduino Uno merupakan sentral dari modul-modul rangkaian pendukung sistem kontrol yang berfungsi untuk mengolah data- data yang dimasukkan ke bagian input arduino dan mengambil tindakan atau keputusan yang hasilnya akan dikirim ke bagian output arduino, atau secara simpel dapat dikatakan kalau arduino berfungsi untuk mengolah data-data inputoutput sistem. Modul relay channel ini mempunyai bagian input maupun output. Fungsi dari modul relay ini adalah sebagai driver yaitu untuk penghubung sumber elemen pemanas dengan sumber daya listrik. Modul relay terhubung langsung dengan bagian output arduinonya. Modul bloetooth hc06 ini adalah menggantikan komunikasi serial menggunakan kabel. Fungsi dari modul bloetooth hc06 ini untuk mengkoneksikan ke aplikasi android sebagai saklar On/off alat tambal ban otomatis ini.

Pada perancangan software ini menggunakan aplikasi program arduino IDE untuk menuliskan program dengan menggunakan bahasa pemrograman $\mathrm{C}++$ arduino uno dan mengedit program serta meng-compile program untuk mengunggah program ke papan arduino uno. Pada rancangan bagian software maka akan berdasarkan pada alur dari proses kerja alat sistem kontrol yang dibuatnya dan proses kerja sistem kontrol secara singkat seperti berikut ini; Pertama kita login aplikasi Android yang bernama Arduino bluetooth controler, setelah login kita koneksikan modul bloetooth HC06 dengan bloetooth hp android, kemudian kita masuk ke menu switch mode untuk mengatur sakelar on/off (1 sebagai on, 2 sebagai off). Setelah itu kita tekan tombol hijau yang berfungsi sebagai ON untuk menghidupkan modul relay yang berfungsi sebagai saklar pemutus/penghubung elemen pemanas yang berfungsi untuk memanaskan atau meatangkan lem perekat ban tersebut.

Alat tambal ban yang terdiri dari beberapa bagian yaitu, Base, Handle dan Pressing/ alat penekan. Bagian-bagian tersebut didesain menggunakan Software Inventor. Instalasi arduino dengan sensor thermokopel sensor thermokopel merupakan bagian input dari sistem kontrol yang berfungsi untuk mendeteksi panas suhu elemen pemanas alat tambal ban. Kaki yang pertama + sebagai sumber daya yang dibutuhkan sensor (+ dihubumgkan dengan pin 5v), kaki yang kedua out sebagai output dari hasil pengolahan data analog sensor (out dihubungkan dengan pin 3) kaki yang 
ketiga - sabagai ground ( - dihubungkan dengan gnd).

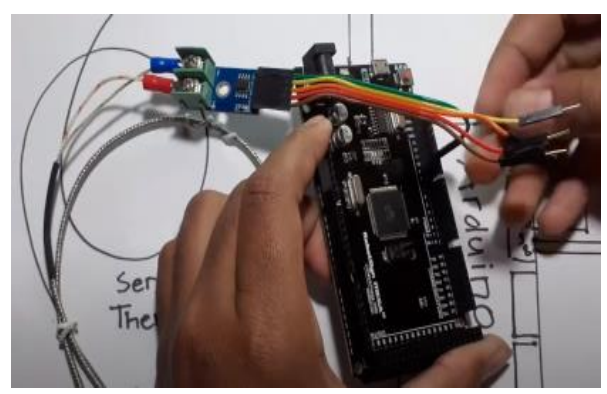

Gambar 5. Rangkaian Arduino Uno

Untuk proses penyusunan program maka pelajari dulu untuk memahami bahasa pemograman yang dipakai dalam aplikasi arduino IDE yang berupa bahasa $\mathrm{C}++$ dan selanjutnya buka/aktifkan dulu aplikasi arduino IDE dengan mengklik icon "ARDUINO" yang ada dalam tampilan dekstop di layar komputer yang selanjutnya akan tampak di layar monitor, seperti tampilan pada gambar di bawah ini.

Pengertian Tambal Ban Berdasarkan Departemen Pendidikan Nasional 2005: 154, tambal merupakan memperbaiki sesuatu rumah, ban, dan sebagainya secara tidak menyeluruh hanya bagian yang rusak. Ban merupakan salah satu komponen kendaraan yang menopang seluruh berat kendaraan dalam berbagai kondisi jalan. Tambal ban merupakan kegiatan memperbaiki ban secara tidak menyeluruh hanya pada bagian yang bocor. Berdasarkan Anugrah Erlangga 2012: 12, ban terdiri dari tiga macam yaitu : a. ban dalam adalah ban yang berada di dalam lebih tipis, tempat udara dipompakan, b. ban luar adalah ban yang berada di luar, tebal, keras sebagai lapis penutup pelindung ban dalam, c. ban tanpa Tubeless adalah ban yang dirancang tanpa menggunakan ban dalam. Berkaitan dengan penelitian ini, ban yang digunakan adalah ban dalam sepeda motor yang sengaja dibocorkan.

Proses atau rangkaian proses yang dirancang untuk memastikan bahwa program computer menjalankan apa yang seharusnya dilakukan dan sebaliknya, memastikan program agar tidak melakukan hal yang tidak diharapkan. Sebuah perangkat lunak seharusnya dapat diprediksi dan konsisten.

Pengujian dilaksanakan dengan mengklik tanda $\sqrt{ }$ (verifikasi) di sudut kiri atas pada aplikasi program arduino IDE dan proses kegiatan ini pada aplikasi IDE dinamakan juga sebagai compile yang berfungsi untuk mengkonversi isi program ke heksadesimal supaya nanti dapat dibaca IC mikrokontroler arduino. Dari proses pengujian/verifikasi program yang sudah disusun sebelumnya maka diperoleh hasilnya yaitu done compiling yang artinya kalau program tersebut sudah benar, seperti yang ditunjukkan pada gambar di bawah ini;

Setelah proses penyusunan program arduino uno sudah selesai dan juga sudah diverifikasi maka perlu pengujian program tersebut dalam proses memasukkan program ke dalam IC mikrokontroler arduino.

Dari pelaksanaan upload program ke IC mikrokontroler arduino diperoleh hasilnya adalah done uploading yang berarti pemindahan program sudah dapat diterima dengan benar. Untuk pengujian hardware dari alat tambal ban sepeda motor yang ergonomis menggunakan arduino uno adalah dengan aplikasi nndroid yang bernama Arduino bluetooth controler.

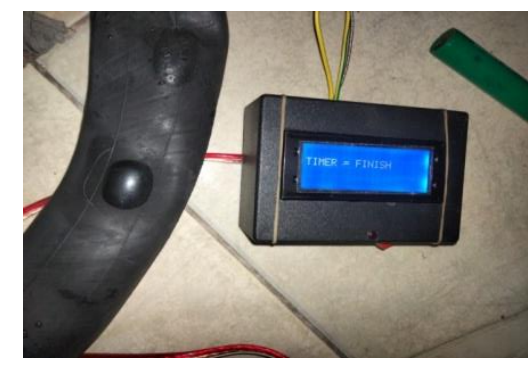

Gambar 6. Pengujian Alat Tambal Ban

Dalam melakukan pengujian alat press ban hal yang ingin dicapai adalah alat press dapat melakukan penekanan pada 
ban dan karet tempel dengan sempurna sehingga hasil dari pemanasan dapat bekerja dengan maksimal adapun langkah melakukan pengujiannya, pertama siapkan karet tempel dan ban dalam yang akan ditempel kemudian pasangkan pada alat press dan letakkan karet press diatas ban , pasang handle pada base dan tekan kebawah bersamaan pemasangan kunci, langkah ini penulis lakukan berulang sehingga didapatkan hasil tekan yang baik, jika karet penekan kurang tekan maka dapat dengan menambahkan karet ban

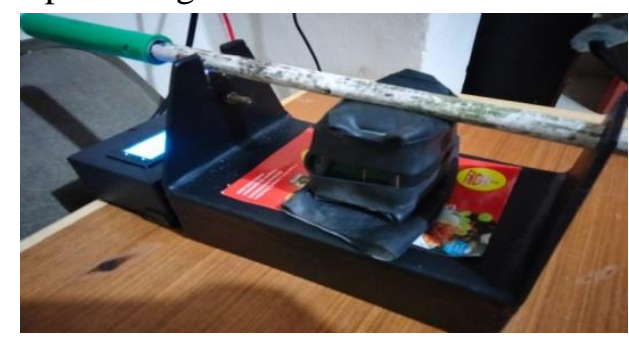

diatas karet press sampai tekanan sesuai.

Gambar 7. Pengujian Alat Press Ban

Saat melakukan pengujian alat press ban didapatkan hasil yang baik karena dengan tekanan sesuai yang diberikan handle dan karet penekan karet ban dapat menempelkan karet lem pada ban dalam dengan sempurna.

Hasil pengujian tambal ban terhadap waktu menggunakan alat uji stopwatch dan thermokopel untuk pengujian suhu yang terpasang pada alat tersebut, dapat dilihat pada garfik sebagai ini;

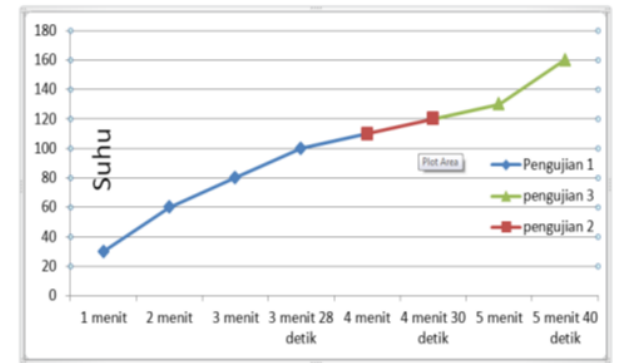

Gambar 8. Grafik perbandingan suhu tambal ban

Pada grafik diatas dapat dilihat bahwa setiap menitnya tambal ban mengalami kenaikan suhu sehingga waktu yang diperlukan untuk menambal ban perlu diuji agar ban dapat masak dengan baik tanpa merusak ban, pengujian dilakukan sebanyak 3 kali saja karena pada pengujian ke tiga sudah didapatkan hasil yang baik, pengujian pertama dengan menggunakan suhu $80-100{ }^{\circ} \mathrm{C}$ membutuhkan waktu 3 menit 28 detik.

Pengujian kedua menggunakan suhu 100-120 ${ }^{\circ} \mathrm{C}$ membutuhkan waktu 4 menit 30 detik dengan hasil tambalan sebagai berikut;

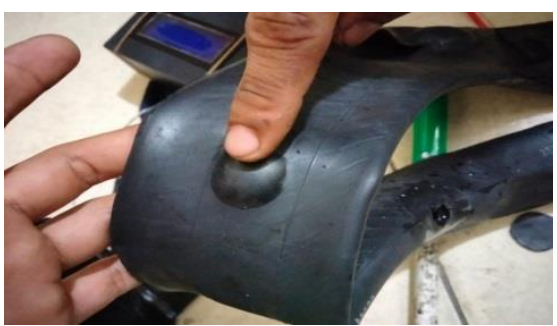

Gambar 9 Hasil Tambal waktu 4 Menit 30 Detik

Dari hasil tambalan gambar 4.26 didapatkan hasil yang kurang baik karena hasil tambalan tidak bisa menahan beban yang besar dan tidak tahan digunakan terlalu lama, sedangkan pada pengujian terakhir atau ketiga menggunakan suhu $120-160{ }^{\circ} \mathrm{C}$ dengan waktu yang dibutuhkan 5 menit 40 detik dengan hasil tambalan seperti gambar berikut ;

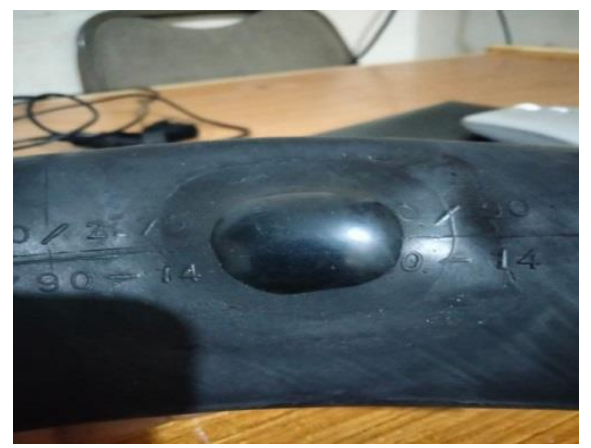

Gambar 10 Gambar Tambal Waktu 5 Menit 40 detik

Dari gambar 4.27 didapatkan hasil yang baik karena karet ban tambal dapat menyatu dengan ban secara sempurna dan dapat menahan beban saat digunakan, pengujian dilakukan sampai yang ketiga

SURYA TEKNIKA Vol. 8 No. 1, Juni 2021: 274-281 
karena melihat dari waktu dan suhu yang digunakan dimana suhu sudah mencapai $160^{\circ} \mathrm{C}$ dan waktu yang dibutuhkan 5 menit 40 detik itu sudah termasuk cukup karena dapat menghemat waktu dan juga pemakaian listrik.

Perancangan yang baik dapat dihasilkan dengan mengenal sifat-sifat, keterbatasan, serta kemampuan yang dimiliki manusia. Manusia berperan sentral dalam aktivitasnya yaitu sebagai perencana, perancang, pelaksana, dan pengevaluasian dalam setiap aktivitas (kerja). Manusia sebagai sumber tenaga kerja masih dominan dalam menjalankan proses produksi terutama kegiatan yang bersifat berulang.

Perancangan peralatan secara ergonomis perlu dilakukan yang berpedoman pada prinsip- prinsip ergonomi (Wignjosoebroto, 2008). Ergonomi dapat didefinisikan sebagai studi tentang aspek-aspek manusia dalam lingkungan kerjanya ditinjau secara anatomi, fisiologi, psikologi, engineering, manajemen, dan desain/perancangan. Ergonomi berkenaan dengan optimasi, efisiensi, kesehatan, keselamatan, dan kenyamanan manusia di tempat kerja, rumah, dan dimana saja manusia berada (Nurmianto, 2004).

Sebelum melakukan perancangan alat juga tentu saja kita harus memperhatikan aspek ergonomi dari alat tersebut. Alat tambal ban ini dirancang sedemikian rupa agar mudah digunakan oleh kalangan masyarakat, seperti bagian handle stick dan base yang dibuat supaya memudahkan memegang pada saat akan melakukan penekanan.

\section{Kesimpulan}

Berdasarkan hasil penelitian dan analisis data maka dapat diperoleh kesimpulan sebagai berikut:

1. Rancang bangun alat tambal ban sepeda motor yang ergonomis menggunakan arduino uno, menunjukkan alat bekerja sesuai dengan rancangannya, dimana masing-masing sensor dapat bekerja dengan baik yang sesuai dengan fungsinya.

2. Alat Tambal Sepeda Motor yang Ergonomis menggunakan Arduino Uno yang terdiri dari beberapa komponen penting diantaranya yaitu; batang penekan sebagai komponen penekan ban, elemen pemanas sebagai sumber panas, arduino, sensor thermokopel, bluetooth, LCD sebagai tampilan monitor panas suhu dan waktu, relay sebagai saklar otomatis, modul bloetooth HC06 sebagai koneksi alat tambal ban.

3. Preventive maintenance yang perlu dalam penelitian ini adalah pada komponen utama hendaklah dilakukan pemeriksaan secara berkala untuk menghindari kerusakan komponen akibat korsleting dan pada plat pemanas pemeriksaan kondisi plat secara teratur agar terhindar dari kerusakan pada lapisan anti lengket (teflon) yang dapat berdampak buruk pada kualitas hasil penambalan.

\section{Daftar Pustaka}

[1] [Manik, Alit, Wastharini., (2010). Perancangan dan Implementasi Sistem Telemetri Suhu Ruangan Berbasis Mikrokontroler.Institut Teknologi Telkom. Bandung.

[2] Ashari, Ahmad, Ana Mufarida, dan Ahmad Efan. (2016). Analisis Perpindahan Panas Pada Alat Tambal Ban Elektrik. Universitas Muhammadiyah Jember. Jember.

[3] Restu, Feria, Rahman Hakim, dan Handika Kurnia Ramadhana. 2020. Rancang Bangun Alat Tambal Ban Sepeda Motor. Technopreneur, 8 (1), 18-25.

[4] Ashari, A, Mufarida, A, \& Efan , A. (2016). Analisis perpindahan panas pada alat tambla ban elektrik. JProteksion, Jurnal Kajian Ilmiah dan Teknologi Teknik Mesin, 1(1), 37-42

[5] Roger S. Pressman. 2007. Rekayasa 
Perangkat Lunak Pendekatan Praktisi (Book Satu). Mc Graw Hill Book co. Andi Offset. Yogyakarta.

[6] Departemen Pendidikan Nasional, 2005 Kamus Besar Bahasa Indonesia edisi

ketiga Balai Pustaka, Jakarta

[7] Setiawan, Iwan., Andjarwirawan, Justinus dan Handojo, Andreas. (2013), Aplikasi Makassar Tourism Pada Kota Makassar Berbasis Android,

Jurnal Infra, 1, 156

[8] Andik giyartono \& Priadhana edi kresnha. 2014. Aplikasi Android Pengendali Lampu Rumah Berbasis Mikrokontroler ATMEGA 328.

[9] (https://scholar.google.co.id/scholar?h l=id\&as_sdt $=0 \% 2 c 5 \&$ as_ylo $=2014 \& s$ cioq/ Di akses 27 oktober 2018, 22: 30 WIT)

[10] Wignjosoebroto, S. (2008). Ergonomi Studi Gerak dan Waktu. Surabaya : Guna Widya.

[11] Nurmianto, Eko. 2004. Ergonomi: Konsep Dasar dan Aplikasinya. Surabaya: Guna Widya 